Psychological Medicine, 1990, 20, 747-754

Printed in Great Britain

EDITORIAL

\title{
The evolution of neurobehavioural complications of HIV infection ${ }^{1}$
}

Changes in mood, behaviour, and neurocognitive functioning can accompany infection by Type 1 Human Immunodeficiency Virus (HIV-1), the causative agent of acquired immune deficiency syndrome (AIDS). Some of these neurobehavioural phenomena reflect attempts to cope with and adapt to knowledge and complications related to a devastating, fatal illness. Others reflect the impact of biological factors on brain function. Elsewhere we have suggested the use of the terms 'psychogenic' and 'neurogenic' to allude to these two broad categories of causation of behavioural disorders (Grant \& Atkinson, 1990).

The neuropsychiatric disturbances that can accompany HIV infection tend to evolve in concert with the natural history of the underlying medical disorder. Fig. 1 presents the idealized relationship of the key processes - underlying deterioration of cell mediated immunity (represented by declining CD4 + lymphocyte numbers), progress of medical symptomatology, mood disturbance, and appearance of neurocognitive disturbance. In general, it can be seen that the 'psychogenic' phenomena (i.e. anxiety, depression, coping difficulties) tend to be most in evidence during transition points in the illness - at the time of discovery of serostatus, during appearance of medical symptoms, and as part of the transition into more serious stages of disease. Disturbance in cognitive function, thought to reflect progress of brain disease, has a low prevalence during the medically asymptomatic phase, with substantial increase during later phases of the illness.

\section{PSYCHOPATHOLOGY IN 'AT RISK' GROUPS}

Before considering neurobehavioural complications of HIV infection it is necessary to understand that, in the Western context, the two major groups which have been at risk for becoming infected with HIV - homosexual men and intravenous drug-users - can also carry with them elevated risk of psychological difficulties which may precede (and, possibly contribute to) becoming infected. Failing to grasp this, we can make the error of ascribing to HIV infection and its consequences, behavioural disorders which might have little to do with the infection per se. For example, research conducted with multiple drug-abusers before HIV came on the scene has demonstrated that the majority can be classified as having personality disorders, including antisocial personality, passive/aggressive or passive/dependent personality, and mixed personality disorders. Structured personality inventories such as the Minnesota Multiphasic Personality Inventory (MMPI) demonstrate elevations in scales 4 and 9 (often linked with antisocial traits), and, in many cases, scales, 2, 7, and 8, indicative of depression, anxiety, low self-esteem, and 'ego boundary' disturbances (Lachar et al. 1978).

With regard to the homosexual risk group, recent data comparing lifetime prevalence of diagnosable psychiatric disorders between seronegative gay men and heterosexual men matched for age and social position indicate that there is substantially more syndromal pathology in the homosexuals compared to the heterosexuals. For example, Atkinson et al. (1989) found that the lifetime prevalence of major depression in a group of seronegative homosexual men was $31 \%$ compared to $9 \%$ in heterosexual men. The figure for the heterosexual group was comparable to estimates of lifetime prevalence for major depression derived from large epidemiological catchment area studies (5\% - Robins et al. 1984). Atkinson et al. (1989) also found that the lifetime prevalence of anxiety disorders (39\%) greatly exceeded that reported among heterosexual men.

\footnotetext{
' Address for correspondence: Dr Igor Grant, San Diego VA Medical Center and University of California, San Diego, La Jolla, California 92093, USA.
} 


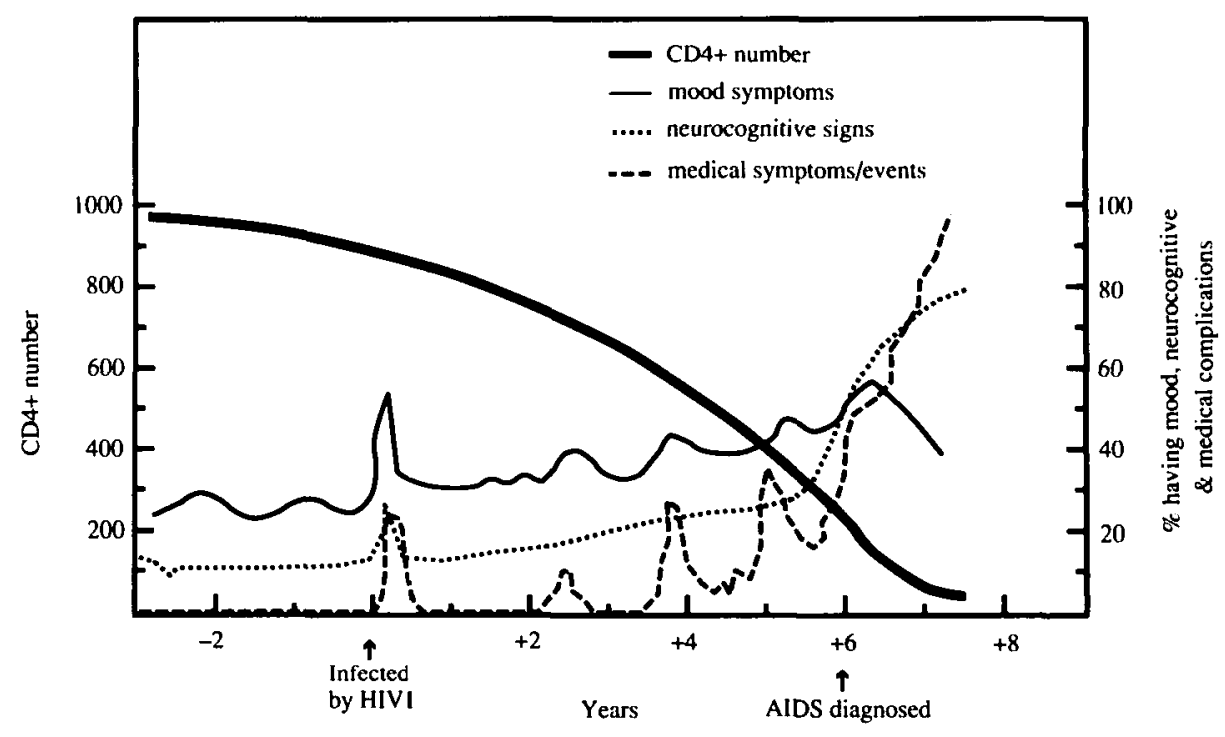

Fig. 1. Progress of medical and neurobehavioural events in HIV-1 infection.

Jacobsberg et al. (1989) also reported an elevated lifetime prevalence of mood disorder (43\%) and personality disorder $(27 \%)$ among persons undergoing HIV antibody testing while Gala et al. (1989) found both higher rates of psychopathology and increased numbers of attempted suicides in HIV negative 'at risk' homosexual men and intravenous drug-users when compared to heterosexual controls.

From the above it appears that anxiety, depression, and personality disturbance occur commonly in persons at risk for HIV infection. Thus, discussion of psychological effects of HIV infection needs to account for this elevated base rate.

\section{SEROCONVERSION PHENOMENA}

Most persons do not know when they became infected with HIV. Indeed, substantial numbers of at risk persons, particularly in the intravenous drug-using group, continue to deny that they could become infected, or alternatively, take the fatalistic viewpoint that they probably are already infected, and therefore should not worry. Still others acknowledge their risk on an intellectual plane but feel powerless to alter their behaviour when swept up in the maelstrom of drug-using or sexual activity that places them at risk.

On the other side of the continuum are the 'worried well' (Miller et al. 1988). These are seronegative individuals (who have often tested repeatedly seronegative) who nevertheless remain convinced that they harbour the infection. The 'worried well' can exhibit a variety of hypochondriacal complaints, including fatigue, vague aches and pains, difficulties with memory and concentration, gastrointestinal and genitourinary symptoms, respiratory complaints, headaches, and other nonspecific symptoms. Counselling and general support are sometimes helpful, especially in a group-therapy setting. In some instances the symptoms and accompanying worry become a constant preoccupation or wax and wane in intensity depending on other circumstances in the person's life.

For persons who actually become infected with HIV, antibody tests will become positive several weeks to several months after exposure (not everyone who is exposed becomes infected, however); also, in rare instances, the delay from infection to seroconversion may be prolonged for a year or more (Imagawa ?t al. 1989). 
At the time seroconversion occurs, some patients experience seroconversion illness, very similar in character to a flu-like syndrome. There may be fatigue, malaise, low-grade fever, aches and pains, and, on occasion, signs of meningeal irritation - headache, photophobia, stiff neck. It is not known whether those who experience meningeal symptoms during seroconversion are more likely to have neurogenic consequences later. From a medical standpoint, the seroconversion illness is transient and the individual returns to his or her ordinary state of health within days or weeks to enter the asymptomatic phase of HIV infection.

\section{DISCOVERY OF SEROSTATUS}

As might be expected the period surrounding antibody testing and notification of results can be stressful. Interestingly, research involving structured questionnaires reveals only modest upswings in anxiety and depression ratings (Jadresik et al. 1989). Studies on coping responses indicate a sense of alienation can accompany recent knowledge of serostatus (Korniewicz et al. 1989). Mood measures tend to normalize in seropositives from nine weeks to six months after notification (Fishman et al. 1989; Jadresik et al. 1989). Persistence of distress in the longer term appears to be inversely related to perceived social support and 'hardiness' (Fishman et al. 1989).

\section{ASYMPTOMATIC AND EARLY SYMPTOMATIC PHASES OF INFECTION}

After seroconversion persons who become HIV antibody positive typically remain free of medical symptoms for a prolonged period of time. While the progress of the underlying infection can be documented by slow decline in CD4 cell numbers, until an individual's count falls to 400 or below medical complications are uncommon. Indeed, many persons remain medically asymptomatic until their CD4 numbers drop to 200 or lower (normal persons generally have numbers above 1000 per cubic $\mathrm{ml}$ ).

There has been considerable attention focused on psychological and neurocognitive characteristics of this asymptomatic period, which typically lasts five to eight years (some remain asymptomatic longer; it is not known whether a person can remain asymptomatic permanently).

While most observers would agree that medically asymptomatic seropositive individuals experience some increase in psychological distress compared to seronegative controls, the qualitative and quantitative features of such distress have depended on specific samples studied and methodologies employed. For example, symptoms of anxiety, determined by self-report checklists (whether self-rated such as the State Trait Anxiety Inventory; or observer-rated, such as the Hamilton) tend to be higher in medically asymptomatic HIV positive persons than HIV negative 'at risk' samples (Atkinson et al. 1989; Coumartin et al. 1989; Herns et al. 1989). Self report of depressive symptoms also tends to be higher in seropositives than seronegatives, though not as elevated as that reported by patients with AIDS Related Complex (ARC) and AIDS (Atkinson et al. 1988; Coumartin et al. 1989; Herns et al. 1989). Individuals with perceived lack of social support tend to be particularly depressed (Ostrow et al. 1989).

If structured psychiatric interviewing and rigorous diagnostic criteria (e.g. Diagnostic Interview Schedule (DIS)) are used to assess mood disorders, then the proportion of persons during this stage who experience anxiety (using a six month incidence for the rate) is approximately $20 \%$ (Atkinson et al. 1988). While this rate is somewhat higher than for seronegative 'at risk' controls (10\%) it is not statistically significantly so; and the latter rate greatly exceeds the negligible six month incidence of diagnosed anxiety among HIV negative heterosexual controls. The incidence of depressive episodes is similar: HIV positive asymptomatic persons are more likely to have an episode of depression (e.g. 6 month incidence of 8 to $19 \%$ in the two studies reported by Atkinson et al. 1988, 1989 , and $13.4 \%$ by Coumartin et al. 1989). Interestingly, these rates are comparable to the $13.9 \%$ six month prevalence of mood disorders recorded for at risk persons undergoing HIV testing (i.e. persons who did not yet know their serostatus - Jacobsberg et al. 1989).

In sum, data on mood disturbance during the medically asymptomatic period indicate that 
$10-20 \%$ of these individuals will experience an episode of anxiety, depression, or both during a preceding six month period. While the rates for seronegatives who are in various 'risk' groups tend to be lower, they still exceed those for matched persons who are 'not at risk'. This indicates that psychiatric phenomenology in the context of asymptomatic HIV infection must be understood as an interaction between predisposition to mood disturbances and response to knowledge of serostatus.

With regard to 'neurogenic' phenomenology, considerable attention has been devoted to determine whether neurocognitive changes can be detected early in the course of the HIV infection. The press to do so has been stimulated by the common observation that perhaps a third of persons with advanced AIDS become clinically demented and another third may manifest subsyndromal pathology in the form of varying degrees of neuropsychological deficit (Grant \& Heaton, 1990).

Early observations by our group indicated that a substantial proportion of medically asymptomatic seropositive persons might have mild neuropsychological deficit (in that study, seven of sixteen such persons had neuropsychological abnormality versus one of eleven HIV negative homosexual controls, Grant et al. 1987). We have also reported increased neuropsychological and brain magnetic resonance imaging (MRI) abnormalities in a recently completed study at St Mary's Hospital and Queen Square (Grant et al. 1990).

While there is general agreement that persons with ARC and AIDS are at heightened risk for neuropsychological and other neurobehavioural abnormalities, the status of persons in the earlier phases of the disease remains controversial (Grant \& Heaton, 1990; Marotta \& Perry, 1989). A review of the most recent presentations on this topic, which occurred at the Fifth International AIDS Conference in Montreal, Canada in June of 1989, shows the number of studies demonstrating some early neurobehavioural abnormality to be about equal to those concluding that HIV positive medically asymptomatic persons are entirely normal from a neurobehavioural standpoint. Among studies reporting positive results, HIV + medically asymptomatic persons have been found to show subtle impairments on neuropsychological tests (Van Dis et al. 1989; Stern et al. 1989; Chave et al. 1989; Clifford et al. 1989; Collier et al. 1989; Martin, A. et al. 1989); abnormalities on reaction time measures (Miller, E. N. et al. 1989 b; Martin, E. et al. 1989); various electrophysiological abnormalities (Koralnik et al. 1989; McAllister et al. 1989; Ollo et al. 1989), eye movement abnormalities (Currie et al. 1989) and abnormality on magnetic resonance imaging (MRI) (Coats et al. 1989; Collier et al. 1989). In addition, a recently published report indicated subtle neuropsychological impairment in seropositive asymptomatic, immunocompetent men when compared to seronegative controls (Perry et al. 1989).

In contrast to research reporting subtle abnormalities in HIV positive asymptomatic persons is an array of studies failing to document such changes. They include neuropsychological investigations (Goethe et al. 1989; Visscher et al. 1989; Selnes et al. 1989; Saykin et al. 1989; Miller, E. N. et al. 1989 a, 1990); as well as reaction time studies (Perdices \& Cooper, 1989) and studies on vibrotactile thresholds (Franzblau, 1989). Data from the US Multicenter AIDS Cohort study also failed to document any MRI differences between HIV positive and negative persons (McArthur et al. 1988,1989 b).

Despite these disagreements, we think it premature to dismiss the positive studies on the basis of sampling problems, methodological defects, and the like. Perhaps the strongest reason for keeping an open mind comes from observations that cerebrospinal fluid (CSF) abnormalities are common in asymptomatic persons. For example, as many as $50 \%$ of HIV positive persons have abnormal numbers of white cells in the CSF and about a quarter have abnormal amounts of protein. Intrablood brain barrier IgG synthesis was reported elevated in $88 \%$ of asymptomatic persons in one study (Singer et al. 1989). Furthermore, these CSF abnormalities appear to be progressive (Marshall et al. 1989a, b; McArthur et al. 1989a). Most worrisome is the fact that HIV can be cultured from the CSF of approximately half of asymptomatic individuals (McArthur et al. 1988). While the presence of virus in the CSF does not prove it is in the brain, such observations, when coupled with frequent (though contradictory) reports of early subtle neurobehavioural ab- 
normalities must continue to be taken seriously. Several large scale prospective studies are now under way, some of which are examining recent seroconverters for whom dates of change in serostatus are reasonably well established. Through such longitudinal multidisciplinary studies it should be possible to arrive at a clearer understanding of the actual risk for neurogenic disturbance in the asymptomatic individual.

\section{FINDINGS IN PATIENTS WITH AIDS AND AIDS RELATED COMPLEX}

With the decline in cellular immunity reaching a point at which opportunistic infections and other diseases become more prominent the patient enters the symptomatic phases of illness, ARC and AIDS. While 'psychogenic' disturbances can continue to be prominent (for example, 20-30\% of patients with AIDS reach criteria for anxiety or depressive disorder, see Perry \& Tross, 1984; Holland \& Tross, 1985), behavioural abnormalities which are secondary to brain disease acquire increasing salience.

Comprehensive neuropsychological testing reveals deficiencies in learning, problem solving, and speeded information processing in roughly half of patients defined as having ARC and up to threequarters of those having frank AIDS (see review by Grant \& Heaton, 1990). It is estimated that approximately one-third of patients with AIDS will develop frank dementia. One prospective study found the two year incidence of clinical dementia in a two year follow-up of ARC/AIDS patients to be $28 \%$ (Day et al. 1989).

The most common causes of central nervous system (CNS) disease are thought to be HIV encephalitis, toxoplasmosis, and co-infection with cytomegalovirus. Many other viruses and pathogens can infect the CNS later in the course of AIDS, and primary lymphomas can also complicate the picture (for review, see Dalakas et al. 1989).

Beside neuropsychological testing, magnetic resonance imaging appears to be particularly sensitive in identifying brain disease early in the course of AIDS. In previous work we noted that $75 \%$ of MRI scans from AIDS patients were abnormal as were $50 \%$ of those with ARC (Grant et al. 1987, 1988). Common patterns of abnormality included multiple focal lesions, larger confluent areas of white matter involvement and basal ganglion involvement, brain atrophy (dilated ventricles, enlarged sulci), and the occasional solitary lesion. Studies with Positron Emission Tomography (PET) suggest that there may be hypermetabolism in subcortical structures earlier in the evolution of the AIDS dementia complex but hypometabolism later (Price et al. 1988).

The manner in which HIV affects the brain is poorly understood. It is evident that neurons themselves are rarely infected, but surrounding cells and mononuclear elements in particular are. On microscopic examination, HIV associated pathology includes 'myelin pallor', and foci of multinucleated giant cells from which HIV can be recovered. Endothelial cells of brain vessels can also be infected, and this may contribute to the pathological process. Wiley et al. (1986) have theorized that infected mononuclear cells may release substances which are toxic to neurons (e.g. tumor necrosis factor and other lymphokines). It may be that fragments of the virus which have homology with neurotrophic factors such as vasoactive intestinal peptide (VIP) may interfere with peptide regulation of neurons. The observation that the gp 120 structural protein of HIV has some similarity to VIP has led to tests with synthetic peptides (e.g. peptide T) which might block the effects of gp 120. At the moment, it is not clear whether therapeutic trials with peptide $T$ will be successful in protecting against CNS disease.

Another intriguing observation has been that quinolinic acid, a neurotoxic metabolite of tryptophan, can be found at higher concentrations in the CSF of HIV-infected persons, particularly those exhibiting neurological signs. This leads to the possibility that HIV may disrupt tryptophan metabolism, shunting the degradation of this biogenic amine through an abnormal biochemical pathway (Heyes et al. 1989).

Another recent observation has suggested that CSF 5-hydroxyindoleacetic acid (a metabolite of serotonin) is decreased in HIV-infected persons. If this is replicated, it is conceivable that some of 
the behavioural disturbances in ARC and AIDS (in particular, depression and apathy) may be related to reductions in brain serotonin activity.

\section{RELATIONSHIP OF ANTI-HIV TREATMENT TO BEHAVIOURAL ABNORMALITY}

The anti-retroviral agent zidovudine (azidothymidine, AZT) can decrease, at least for a time, medical complications and prolong life in HIV-infected persons. To what extent drugs such as zidovudine can also protect against or reverse neurological complications remains unclear. There have been reports of neuropsychological improvement in AZT treated persons compared to controls (Schmitt et al. 1988; Price et al. 1989; Sidtis et al. 1989). On the other hand, our study on incidence of dementia showed that $28 \%$ of AIDS and ARC patients developed clinical dementia despite most of them having received zidovudine (Day et al. 1989). Thus, while current antiretroviral agents might slow, or even temporarily benefit, neuropsychiatric sequelae, the long range prognosis may not be so favourable.

\section{SUMMARY : CHALLENGES FOR THE FUTURE}

HIV infection can produce a neurobehavioural disorder as well as an immunological disease. Persons at various stages of HIV infection are more likely to have symptomatic anxiety, depression, adjustment disorders, and other behavioural disturbances. While some of these 'psychogenic' changes clearly can be related to knowledge of HIV infection and its probable consequences, they should not all be ascribed to the stress of illness. Rather, in Western societies at least, those who are at risk for HIV infection also appear to have higher background rates of psychological disturbances. Thus, the evaluation and management of psychiatric disturbances needs to take into account these two likely factors in the aetiology of current problems.

HIV infection also brings with it the burden of direct injury of the central nervous system with consequent impact on neurocognitive functioning. Medically asymptomatic or mildly symptomatic persons may have a small but significant risk for neurobehavioural disturbance compared to seronegatives; however, the data here remain conflicting. By the time an individual reaches ARC or AIDS, the likelihood of such disturbance increases substantially. Neurobehavioural abnormalities can range from subtle disturbances in cognitive function (memory and speeded information processing in particular) to frank dementia which has often been described as having 'subcortical' features - i.e. a greater weight of symptoms in the areas of slowed information processing, defective learning, but with sparing of language ability until later stages).

There are many important directions for future research, but several are of particular relevance to those involved in psychological medicine. A pressing need is to define the incidence, qualitative features, and natural history of CNS involvement of HIV infection; to determine whether there are 'neurotropic' strains of HIV; to document the importance of co-infection with other viruses; and to elucidate host factors (genetic, constitutional, previous medical history) which may facilitate CNS disease. Additional research needs to address the role of stress in speeding progress of disease, and its neurobehavioural consequences.

In summary, the tragedy of HIV presents both opportunities and challenges to investigators and practitioners of psychological medicine to contribute to improved characterization, treatment, and prevention of AIDS and its neurobehavioural consequences.

IGOR GRANT AND J. HAMPTON ATKINSON

This work was supported in part by NIMH grants 1-RO1-MH43298 and 1-P50-MH45294.

We thank Ms Steffanee White and Ms. Kathy Stuart for their assistance in typing the manuscript. 


\section{REFERENCES}

Atkinson. J. H., Grant, I.. Kennedy, C. J., Richman, D. D., Spector, S. A. \& McCutchan, J.A. (1988). Prevalence of psychiatric disorders among men infected with human immunodeficiency virus: a controlled study, Archives of General Psychiatry 45, 859864.

Atkinson, H., Grant, I., Heaton, R. \& Weinrich, J. (1989). Psychiatric disorder and HIV infection: a controlled longitudinal study. Fifth International Conference on AIDS Montreal, Canada. June, 1989.

Chave, J.. Thuillard, F.. Assal, G. \& Glauser, M.P. (1989). Neuropsychological manifestations on HIV infection: a prospective study. Fifth International Conference on AIDS Montreal, Canada. June, 1989.

Clifford, D., Miller, J. P., Seyfried, W., Glickman, M. \& Jacoby, R. (1989). Neuropsychometric function in early HIV positive patients compared with a matched HIV negative population. Fifth International Conference on AIDS Montreal, Canada. June, 1989.

Collier, A., Marra, C., Coombs, R., Cohen, W., Claypoole, K. \& Handsfield, H. (1989). Central nervous system findings and neurologic correlates of HIV infection in men with CDC group II/III HIV disease. Fifth International Conference on AIDS Montreal, Canada. June, 1989.

Coats, M., Sulazar, A. M., Martin, A., Jabbari, B., Geyer, C. \& Burke, D. (1989). Neurological findings in early HIV infection. Fifth International Conference on AIDS Montreal, Canada. June, 1989.

Coumartin, S., Tal, M., Joseph, J. \& Kessler, R. (1989). Psychological and social functioning in a cohort of homosexual men at risk for AIDS. Fifth International Conference on AIDS Montreal, Canada. June, 1989.

Currie, J., Ramsden, B. M., Lynch, J. M., McArthur, C. L., Benson, E. M. \& Perdices, M. (1989). Antisaccadic eye movement abnormalities in asymptomatic HIV seropositive individuals. Fifth International Conference on AIDS Montreal, Canada. June, 1989.

Dalakas, M., Wichman, A. \& Sever, J. (1989). AIDS and the nervous system. Journal of the American Medical Association 261, 23962399.

Day, J.. Grant, I., Atkinson, H., Brysk, L., McCutchan, J. A., Hesselink, J., Heaton, R. K., Spector, S. \& Richman, D. (1989). Neurological follow-up of subjects on AZT licensing trial: San Diego cohort. Fifth International Conference on AIDS Montreal, Canada. June, 1989.

Fishman, B., Perry, S., Jacobsberg, L. \& Frances, A. (1989) Psychological factors predicting distress after HIV testing. Fifth International Conference on AIDS Montreal, Canada. June, 1989.

Franzblau, A., Letz, R. E., Hershman, D., Mason, P., Wallace, J. \& Bekesi, J.G. (1989). Quantitative vibration threshold testing (QVTT) and computer-based neurobehavioral testing (NES) of persons infected with HIV. Fifth International Conference on AIDS Montreal, Canada. June, 1989.

Gala, C., Martini, S., Pergami, A., Rossini, M., Russo, R. \& Lazzarin, A. (1989). Psychiatric history among homosexuals and drug-addicts infected with human immunodeficiency virus. Fifth International Conference on AIDS Montreal, Canada. June, 1989.

Goethe, K. R., Mitchell, J. E., Marshall, D. W., Brey, R. L., Cahill, W. T., Leger, D., Hoy, L. J. \& Boswell, R. N. (1989). Neuropsychological and neurological function of human immunodeficiency virus seropositive asymptomatic individuals. Archives of Neurology 46, 129-133.

Grant, I. \& Atkinson, J. H. (1990). Neurogenic and psychogenic behavioral correlates of HIV infection. In Immunological Mechanisms in Neurologic and Psychiatric Disease (ed. B. H. Waksman), pp. 291-304. Raven Press: New York.

Grant, I. \& Heaton, R. (1990). Human immunodeficiency virus-1 (HIV-1) and the brain. Journal of Consulting and Clinical Psychology 58, 22-30.

Grant, I., Atkinson, J. H., Hesselink, J. R., Kennedy, C. J., Richman, D. D., Spector, S. A. \& McCutchan, J. A. (1987). Evidence for early central nervous system involvement in the acquired immunodeficiency syndrome (AIDS) and other human immunodeficiency virus (HIV) infections. Studies with neuropsychologic testing and magnetic resonance imaging. Annals of Internal Medicine 107, 828-836.

Grant, I., Atkinson, J. H., Hesselink, J. R., Kennedy, C. J., Richman, D. D., Spector, S. A. \& McCutchan, J. A. (1988). Human immunodeficiency virus-associated neurobehavioural disorder. Journal of the Royal College of Physicians of London 22, 148-157.

Grant, 1., Caun, K., Kingsley, D., MacDonald, W. I., Pinching, A. J. \& Trimble M. (1990). Neuropsychological and NMR abnormalities in HIV infection: a preliminary report from the St Mary's-Queen Square Collaborative Study (in the press).

Herns, M., Newman, S., McAllister, R., Weller, I. \& Harrison, J. (1989). Mood state, neuropsychology and self reported cognitive deficits in HIV infection. Fifth International Conference on AIDS Montreal, Canada. June, 1989.

Heyes, M. P., Brew, B. J., Karkey, S. P., Martin, A., Price, R. W., Rubinow, D. \& Salazar, A.M. (1989). Quinolinic acid concentrations are increased in plasma and cerebrospinal fluid in AIDS as correlates with AIDS dementia complex. Fifth International Conference on AIDS Montreal, Canada. June, 1989.

Holland, J.C. \& Tross, S. (1985). The psychosocial and neuropsychiatric sequelae of the acquired immunodeficiency syndrome and related disorders. Annals of Internal Medicine 103, 760-764.

Imagawa, D. T., Lee, M. H., Wolinsky, S. M., Sano, K., Morales, F., Kwok, S., Sninsky, J. J., Nishanian, P. G., Giorgi, J. \& Fahey, J. L. (1989). Human immunodeficiency virus type-1 infection in homosexual men who remain seronegative for prolonged periods. New England Journal of Medicine 320, 1458-1462.

Jadresik, D., Riccio, Massimo, Hawkins, D., Wilson, B. \& Thompson, C. (1989). Impact of HIV diagnosis on mood - St Stephen's cohort study. Fifth International Conference on AIDS Montreal, Canada. June, 1989.

Jacobsberg, L., Perry, S., Fishman, B., Frances, A., Ryan, J. \& Fogal, K. (1989). Psychiatric diagnosis among volunteers for HIV testing. Fifth International Conference on AIDS Montreal, Canada. June, 1989.

Koralnik, I., Heaumanoir, A., Hausler, R., Kohler, A., Delacoux, R. \& Hirschel, B. (1989). Abnormalities of EEG and otoneurologic tests in asymptomatic HIV infected homosexuals: a prospective controlled study. Fifth International Conference on AIDS Montreal, Canada. June, 1989.

Korniewicz, D. (1989). Psychosocial adaptation among HIV positive patients. Fifth International Conference on AIDS Montreal, Canada. June, 1989.

Lachar, D., Schooff, K., Keegan, J. \& Gdowski, C. (1978). Dimensions of polydrug abuse: an MMPI study. In Polydrug Abuse: The Results of a National Collaborative Study (ed. Donald R. Wesson, Albert S. Carlin, Kenneth M. Adams and George Beschner), pp. 149-180. Academic Press: New York.

McAllister, R. H., Harrison, M. J. G., Griffin, G. B., Fowler, C. J., Newman, S. P., Herns, M. V. \& Weller, I. V. D. (1989). Prospective neurological, and neuropsychological assessment in a cohort of homosexual men. Fifth International Conference on AIDS Montreal, Canada. June, 1989.

McArthur, J. C., Cohen, B. A., Farzadegan, H., Cornblath, D. R. Selnes, O. A., Ostrow, D., Johnson, R. R., Phair, J. \& Polk, B. F. (1988). Cerebrospinal fluid abnormalities in homosexual men with and without neuropsychiatric findings. Annals of Neurology 23 (suppl.), S34-S37.

McArthur, J. C., McArthur, J. H., Herman, C., Farzadegan, H., Margolick, J. \& Saah, A. $(1989 a)$. Increasing CSF abnormalities in HIV-1 infected individuals with declining systemic immune status. Fifth International Conference on AIDS Montreal, Canada. June, 1989.

McArthur, J. C., Cohen, B. A., Selnes, O. A., Kumar, A. J., Cooper, K., McArthur, J. H., Soucy, G., Cornblath, D. R., Chmiel, J. S., Wang, M.-C., Starkey, D. L., Ginzburg, H., Ostrow, D. G., Johnson, R. T., Phair, J. P. \& Polk, B. F. (1989 b). Low prevalence of neurological and neuropsychological abnormalities in otherwise 
healthy HIV-1-infected individuals: results from the Multicenter AIDS Cohort Study. Annals of Neurology 26, 601-611.

Marotta, R. \& Perry, S. (1989). Early neuropsychological dysfunction caused by human immunodeficiency virus. Journal of Neuropsychiary 1, 225-235.

Marshall, D. W., Brey, R. L., Butzin, C. A., Lucey, D. R. \& Boswell, R. N. (1989a). Intrathecal production of IgG in a longitudinal study of 258 HIV-infected US Air Force personnel. Fifth International Conference on AIDS Montreal, Canada. June, 1989.

Marshall, D. W., Brey, R. L., Butzin, C. A., Zajaz, R. A. \& Boswell, R. N. (1989 $b$ ). Longitudinal CSF cell counts and protein levels in 258 HIV-infected US Air Force personnel. Fifth International Conference on AIDS Montreal, Canada. June, 1989.

Martin, A., Salazar, A. M., Kampen, D., Williams, J., Law, W. \& Gomes, C. (1989). Patterns of neuropsychological dysfunction in a select group of HIV positive individuals in comparison to psychiatric controls. Fifth International Conference on AIDS Montreal, Canada. June, 1989

Martin, E. M., Edelstein, H. \& Robertson, L. (1989). Decisionmaking speed in early human immunodeficiency virus (HIV) infection. Fifth International Conference on AIDS Montreal, Canada, June, 1989.

Miller, D., Acton, T. M. G. \& Hedge, B. (1988). The worried well: their identification and management. Journal of The Royal College of Physicians of London 22, 158-165.

Miller, E. N., Selnes, O. A., Visscher, B., McArthur, J. C., Satz, P. \& Dudley, J. (1989a). Changes in performance on the trail-making test before and after HIV-1 seroconversion and diagnosis of AIDS; the Multicenter AIDS Cohort Study (MACS). Fifth International Conference on AIDS Montreal, Canada. June, 1989.

Miller, E. N., Satz, P., Van Gorp, W., Visscher, B. \& Dudley, J. $(1989 b)$. Computerized screening for HIV-related cognitive decline: cross-sectional analyses and one-year follow-up. Fifth International Conference on AIDS Montreal, Canada. June, 1989.

Miller, E. N., Selnes, O. A., McArthur, J. C., Satz, P., Becker, J. T., Cohen, B. A., Sheridan, K., Machado, A. M., Van Gorp, W. G. \& Visscher, B. (1990). Neuropsychological performance in HIV-1. infected homosexual men: the Multicenter AIDS Cohort Study (MACS). Neurology 40, 197-203.

Ollo, C., Johnson, R., Jr., Grafman, J., Govonj, L., Rubinow, D. \& Bridge, P. (1989). Event-related potential measures of dementia in HIV disease. Fifth International Conference on AIDS Montreal, Canada. June, 1989.

Ostrow, D. G., Monjan, A., Joseph, J., VanRaden, M., Fox, R., Kingsley, L., Dudley, J. \& Phair, J. (1989). HIV-related symptoms and psychological functioning in a cohort of homosexual men. American Journal of Psychiatry 146, 737-742.

Perdices, M. \& Cooper, D. (1989). Choice-reaction time measures and cognitive dysfunction in persons with HIV infection. Fifth International Conference on AIDS Montreal, Canada. June, 1989.

Perry, S., Belsky-Barr, D., Barr, W. B. \& Jacobsberg, L. (1989). Neuropsychological function in physically asymptomatic, HIV. seropositive men. Journal of Neuropsychiatry, 1, 296-302.

Perry, S. W. \& Tross, S. (1984). Psychiatric problems in AIDS inpatients at the New York Hospital: preliminary report. Public Health Report 99, 200-205.
Price, R. W., Brew, B., Sidtis, J., Rosenblum, M., Scheck, A. C. \& Cleary, P. (1988). The brain in AIDS: central nervous system HIV$I$ infection and AIDS dementia complex. Science 239, 586592.

Price, R. W., Koch, M. A., Sidtis, J. J., Feinburg, J., Collier, A., Kennedy, C., Singer, E. \& Price, S. (1989). Zidovudine (AZT) treatment of the AIDS dementia complex (ADC): results of a placebo-controlled, multicentered therapeutic trial. Fifth International Conference on AIDS Montreal, Canada. June, 1989.

Robins, L. N., Helzer, J. E., Weissman, M. M., Orvaschel, H., Gruenberg, E., Burke, J. D. \& Regier, D. A. (1984). Lifetime prevalence of specific psychiatric disorders in three sites. Archives of General Psychiatry 41, 949958.

Saykin, A. J., Janssen, R., Sprehn, G., Spira, T., Cannon, L., Kaplan, J., O'Connor, B., Watson, S. \& Allen, R. (1989). Neuropsychological and psychosocial function in two cohorts of gay men: relation to stage of HIV infection. Fifth International Conference on AIDS Montreal, Canada. June, 1989.

Schmitt, F. A., Bigley, J. W., McKinnis, R., Logue, P. E., Evans, R. W. \& Drucker, J. L. (1988). Neuropsychological outcome of zidovudine (AZT) treatment of patients with AIDS and AIDSrelated complex. New England Journal of Medicine 319, 15731578.

Selnes, O., McArthur, J. C., Miller, E. N., Sheridan, K., Becker, J. T. \& Gordon, B. (1989). Further evidence of lack of HIV-I related cognitive impairment during the asymptomatic stages: the multicenter AIDS Cohort Study (MACS). Fifth International Conference on AIDS Montreal, Canada. June, 1989.

Sidtis, J. J., Sadler, A. E., Keilp, J., Brew, B. J., Aronow, H. A. \& Price, R. W. (1989). Neuropsychological test performance on HIV. 1 seropositive patients on and off azidothymidine (AZT). Fifth International Conference on AIDS Montreal, Canada. June, 1989.

Singer, E. J., Syndulko, K., Ruane, P., Mitsuyasu, R., Chandon, B. S., Resnick, L., Shapshak, P. \& Tourtellotte, W. W. (1989). Cerebrospinal fluid and blood markers in HIV seropositive individuals with and without neurologic complications. Fifth International Conference on AIDS Montreal, Canada. June, 1989.

Stern, Y., Sano, M., Goldstein, S., Minry, D., Richards, M., Todak, G., Williams, J. B. W., Erdhardt, A. \& Gorman, J. (1989). Neuropsychological manifestations of HIV infection in gay men. Fifth International Conference on AIDS Montreal, Canada. June, 1989.

Van Dis, H., vas Beuzekom, M., de Wolf, F. \& Coutinbo, R. A. (1989). Neuropsychological deficits associated with asymptomatic HIV infection. Fifth International Conference on AIDS Montreal, Canada. June, 1989.

Visscher, B. R., Miller, E., Satz, P., McArthur, J., Selnes, O., Cohen, B., Becker, J., English, P. \& Nance-Sproson, L. (1989). Neuropsychological follow-up of 1787 participants in the Multicenter AIDS Cohort Study. Fifth International Conference on AIDS Montreal, Canada. June, 1989.

Wiley, C. A., Schrier, R. D., Nelson, J. A., Lampert, P. W. \& Oldstone, M. B. A. (1986). Cellular localization of human immunodeficiency virus infection within the brains of acquired immune deficiency syndrome patients. Proceedings of the National Academy of Science 83, 7089-7093. 